\title{
Screening of Resistance Cultivar to Clubroot Caused by Plasmodiophora brassicae for Organic Cultivation of Chinese Cabbage
}

\author{
Min-Jeong Kim, Chang-Ki Shim*, Yong-Ki Kim, Sung-Jun Hong, Jong-Ho Park, \\ Eun-Jung Han, Min-Ho Lee and Hyeong-Jin Jee \\ Organic Agriculture Division, National Academy of Agricultural Science, Suwon 441-707, Korea \\ (Received on April 26, 2012; Revised on May 18, 2012; Accepted on May 23, 2012)
}

\begin{abstract}
We investigated the resistance of 50 commercial Chinese cabbage cultivars against clubroot disease caused by Plasmodiophora brassicae in the three difference fields, Suwon, Hwacheon, and Pyeongchang. Wilting symptom on Chinese cabbage was first observed at 15 days after transplanting in Pyeongchang and Hwacheon, while disease symptoms appeared later in Suwon after the rainy season. Among 50 cultivars, eight cultivars, SC26, SC29, SC30, SC31, SC34, SC46, SC47 and SC50 showed highly susceptible symptoms like wilting and heavy root galls in all three fields. Meanwhile, seven cultivars such as SC05, SC06, SC07, SC09, SC11, SC17, and SC36 showed moderate resistance with delayed wilting and few root galls. Only two cultivars, Chuwol (CB22) and Gohyangssam (CB23) were highly resistant to clubroot disease until the harvest season in all of the three fields. These two commercial cultivars may be considered as candidate cultivars for cultivation of organic Chinese cabbage in Suwon, Hwacheon, and Pyeongchang.
\end{abstract}

Keywords : Bioassay, Brassica campestris ssp. pekinenesis, Plasmodiophora brassicae

The clubroot disease, caused by Plasmodiophora brassicae, brings serious yield loss, accounting for a $10-15 \%$ reduction in yield on a global scale in cruciferous crops including Chinese cabbage, radish, turnip, and cabbage. This is attributed to the increase in population density of the pathogen with their continuous monoculture in intensive production areas (Dixon, 2009; Kim et al., 2003; Yoshikawa, 1981).

In Korea, clubroot disease was first reported in the 1920 s, and caused severe economic losses in many Brassica growing areas since the early 1990s. Recently, the disease become a more serious problem in monocropping and extensively cultivated areas including highland areas (Kim and Oh, 1997; Kim et al., 1999).

The obligate biotrophic clubroot pathogen, Plasmodiophora brassicae, shows a wide variability in pathogenicity and has an intricate interaction with its host in some parts of the infection process. The disease is easy to inadvertently spread to previously non-infected fields via infected transplanting materials. Also, the disease can be moved long distances, and foreign pathotypes can be introduced (Dixon, 2009; Kim et al., 2003).

*Corresponding author

Phone) +82-31-290-0545, Fax) +82-31-290-0507

Email)ckshim@korea.kr
To control the clubroot disease, various practical techniques have been tried such as resistant varieties, biological control agents, and crop rotation systems (Donald et al., 2006; Tremblay et al., 1999; Yeoung et al., 2003; Yoon et al., 2010). Chemical control is limited, since the few effective treatments are either banned or too expensive. Because the pathogen survives as resting spores for long time periods in the soil, it is hard to control the disease by cultural practice or agrochemicals (Donald et al., 2006).

Many applications of soil amendments like lime, egg shell, calcium and boron to decrease the $\mathrm{pH}$ of the soil were investigated to reduce disease pressure, but these treatments are often not sufficient to keep the crop healthy (Davis and Jones, 2002; Hamilton and Crête, 1978).

Since high-resistance resources have not been found among varieties of Chinese cabbage, several breeding programs have been successfully carried out to develop clubroot resistant (CR) cultivars of Chinese cabbage using CR European turnips (Brassica rapa ssp. rapifera) as sources of resistance (Hirai, 2006; Lee et al., 2001; Yoshikawa, 1981).

Hereditary clubroot resistance to cabbage crops has been reported but growing resistant Brassica cultivars is another widely used alternative (Hirai, 2006). The 
use of disease resistant varieties is one of the most convenient, inexpensive, and environment friendly ways to control plant disease, and plant breeders make extensive use of classically defined $R$ genes (Pia et al., 2004; Yoshigawa, 1981).

However, these clubroot resistant (CR) hybrid cultivars have become susceptible to clubroot in some field trials (Pia et al., 2004). Moreover, only a small number of resistant cultivars have been released. Breeding programs aimed at the introduction of resistance to clubroot have been few and the results were often disappointing (Cho et al., 2002; Voorrips, 1995). Yoon et al. (2010) reported that among 34 cultivars and 19 lines of Chinese cabbage, three cultivars, namely, Daetong, Super CR Kimi 85 and Super CR Hiroki, were resistant to clubroot at 60 days after transplanting in the highland field contaminated with P. brassicae in Korea.

This study was carried out to screen resistant cultivars of Chinese cabbage against clubroot disease for safe production of organic Chinese cabbage.

We investigated the resistance of 50 commercial Chinese cabbage cultivars against clubroot disease caused by $P$. brassicae in the three difference fields, Suwon, Hwacheon, and Pyeongchang. The three open fields of Suwon, Hwacheon, and Pyeongchang are usually infected with natural inocula of $P$. brassicae. Legume hairy vetch (Vicia villosa Roth) was cultivated in Suwon, while rye grass (Secale cereale) was grown in Pyeongchang as green manure crops over the winter season from 2009 to 2011. The whole amount of green manure was thoroughly incorporated into the field soil before the addition of organic fertilizer nutrients. Organic fertilizer $\left(2,500 \mathrm{~kg} / 1000 \mathrm{~m}^{2}\right)$ and mixed expeller cake $(1,000 \mathrm{~kg} /$ $1000 \mathrm{~m}^{2}$ ) were added in each field.

The physico-chemical characteristics of the three fields were analyzed using the standard soil analysis method. The level of $\mathrm{P}_{2} \mathrm{O}_{4}$ in the soil was determined by colorimeter. The contents of exchangeable cations $\mathrm{K}^{+}$, $\mathrm{Na}^{+}, \mathrm{Ca}^{2+}$ and $\mathrm{Mg}^{2+}$ were quantified by atomic absorption spectroscopy (Perkin-Elmer Atomic Absorption Spectrometer 3300, Ueberlingen, Germany). The electrical conductivity (EC) and $\mathrm{pH}$ were also determined in a soil to distilled water ratio of 1:5.
A total of 50 commercialized Chinese cabbage cultivars were purchased from ten seed companies such as Nongwoo (17), Danong (10), Hungnong (9), Sakada (4), Syngenta (2), Hannong (2), Jungang (2), Daenong (2), Nonghyup (1), and Asia (1). Those of Chinese cabbage cultivars were used to determine clubroot disease resistance in 2011. After disinfecting with $2 \%$ sodium hypochlorite $(\mathrm{NaOCl})$, the seeds were germinated at $28^{\circ} \mathrm{C}$ in a saturated humidity chamber. The pre-germinated seeds were sown into 72 cells plastic seedling trays and grown for about 35 days in the greenhouse.

Fifteen replicates of 35-day-old Chinese cabbage seedlings per each cultivar were transplanted into the three fields naturally infested with clubroot pathogens. Disease severity was determined for 49 days with 7 days interval after transplanting. The disease severity of clubroot symptoms was assessed by assigning symptom grades based on visual inspection and measurement of healthy and diseased root tissues. Disease severity was classified into four categories according to the following criteria: resistant, no club symptoms; moderately resistant, less than $20.0 \%$ disease severity; susceptible, 20.1$66.7 \%$ disease severity; highly susceptible, more than $66.8 \%$ disease severity.

After treatment of green manure and soil amendments, the physico-chemical properties of the three field soils were determined in Table 1 . The soil $\mathrm{pH}$ of the three fields was slightly increased for acidic soil after applying of Dolomite $\left(20 \mathrm{~kg} / 1000 \mathrm{~m}^{2}\right)$ and egg shells $(25 \mathrm{~kg} /$ $1000 \mathrm{~m}^{2}$ ) (Table 1). The $\mathrm{pH}$ of the three fields was 5.1 (Pyeongchang), 6.2 (Suwon), and 6.5 (Hwacheon), respectively. The highest EC was found in Hwacheon $(151.8 \mathrm{ds} / \mathrm{m})$ followed by Pyeongchang $(143.9 \mathrm{ds} / \mathrm{m})$, and Suwon $(99.29 \mathrm{ds} / \mathrm{m})$. Concentration of organic material $(\mathrm{OM})$ in the three fields ranged from $1.83 \%$ to $2.27 \%$, with Suwon having the highest OM concentration among the three fields. All three open fields had comparably exchangeable cation concentration which was equivalent to what was found in the agriculturally controlled soil for Chinese cabbage. Davis and Jones (2002) reported that the organic amendments, straw and chitin significantly reduced clubroot symptoms compared to other amendments including unamended treatment.

Table 1. Soil characteristics of Chinese cabbage cultivation fields tested for screening of clubroot resistance under the presence of green manure

\begin{tabular}{|c|c|c|c|c|c|c|c|c|c|c|}
\hline \multirow{2}{*}{ Location } & \multicolumn{2}{|c|}{ Green manure } & \multirow{2}{*}{$\begin{array}{c}\mathrm{pH} \\
(1: 5)\end{array}$} & \multirow{2}{*}{$\begin{array}{c}\text { E.C } \\
(\mathrm{ds} / \mathrm{m})\end{array}$} & \multirow{2}{*}{$\begin{array}{l}\mathrm{OM} \\
(\%)\end{array}$} & \multirow{2}{*}{$\begin{array}{c}\mathrm{Av} \cdot \mathrm{P}_{2} \mathrm{O}_{5} \\
(\mathrm{mg} / \mathrm{kg})\end{array}$} & \multicolumn{4}{|c|}{ Ex. Cation $(\mathrm{cmol} / \mathrm{kg})$} \\
\hline & 2009 & 2010 & & & & & $\mathrm{~K}$ & $\mathrm{Mg}$ & $\mathrm{Na}$ & $\mathrm{Ca}$ \\
\hline Suwon & Hairy Vetch & Hairy Vetch & & $99.29( \pm 2.4)$ & $2.27( \pm 0.7)$ & & $1.0( \pm 0.6)$ & $2.6( \pm 0.6)$ & $0.1( \pm 0.07)$ & $8.2( \pm 0.08)$ \\
\hline Hwacheon & Rye grass & Rye grass & $6.5( \pm 0.04)$ & & $1.88( \pm 0.2)$ & $658.9( \pm 0.8)$ & $0.7( \pm 0.1)$ & $1.7( \pm 0.1)$ & $0.1( \pm 0.08)$ & $6.5( \pm 0.05)$ \\
\hline Pyeongchang & Rye grass & Rye grass & $5.1( \pm 0.02)$ & $143.94( \pm 4.1)$ & $1.83( \pm 0.6)$ & $649.8( \pm 0.4)$ & $0.8( \pm 0.3)$ & $2.8( \pm 0.7)$ & $0.2( \pm 0.08)$ & $9.5( \pm 0.03)$ \\
\hline
\end{tabular}




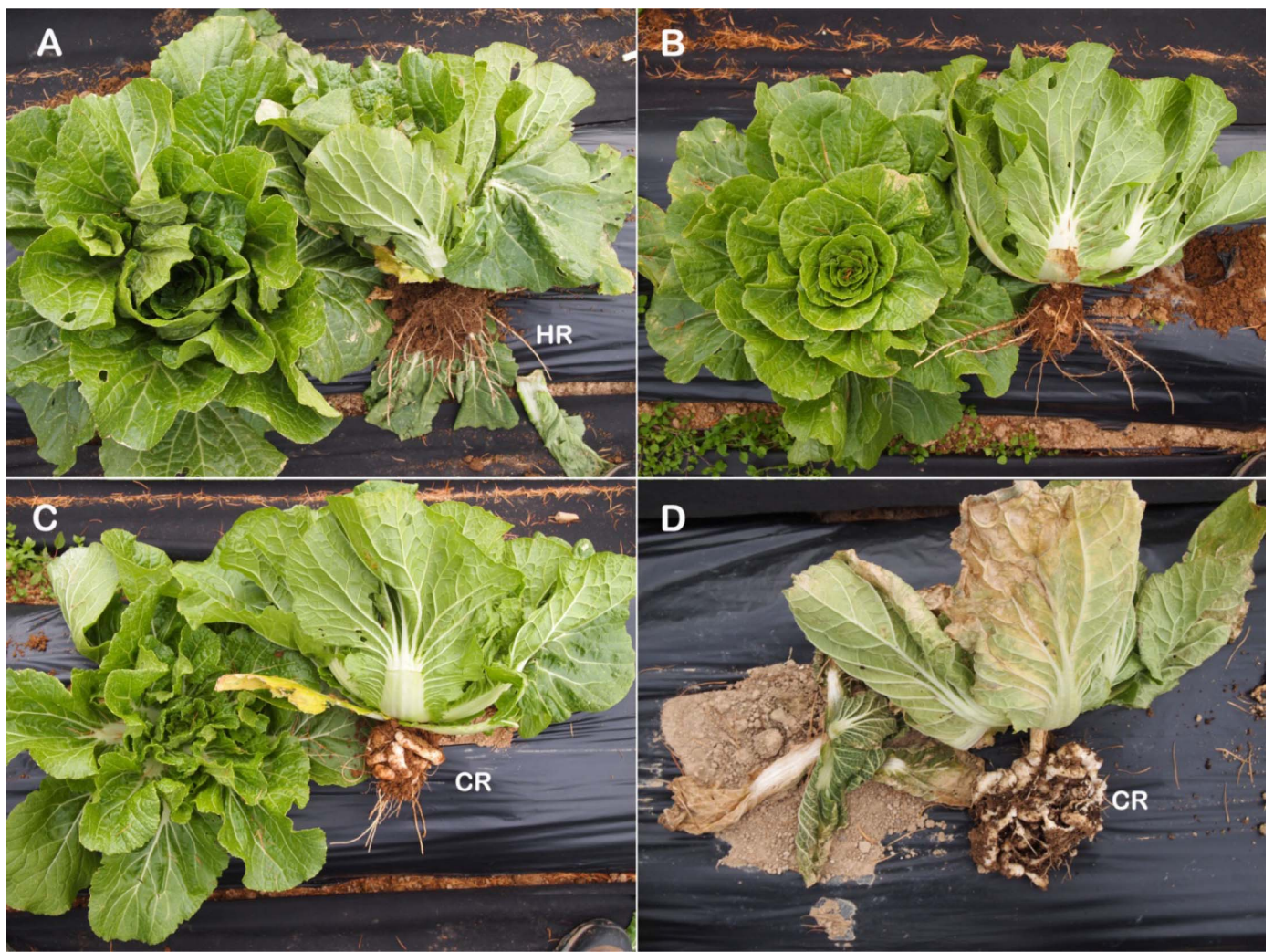

Fig. 1. Symptom grades of clubroot, resistant (A, SC22), moderately resistant (B, SC05), susceptible (C, SC48) and highly susceptible (B, SC50) of Chinese cabbage cultivars based on disease severity of clubroot caused by Plasmodiophora brassicae at 35 days after transplanting. HR: healthy root, CR: clubbed root.

Also, the effects are probably due to a combination of $\mathrm{pH}$ effects on the clubroot disease and nutrients effects on the Chinese cabbage.

Clubroot-infected Chinese cabbage plants are usually wilted and dwarfed compared to healthy plants. When infected plants are pulled out of the soil, the root system shows typical gall formation. At maturity, the galls turn brown and a large portion of the infected roots remains under ground when the plants are harvested (Fig. 1).

Among 50 Chinese cabbage cultivars, eight cultivars (SC26, SC29, Sc30, Sc31, SC34, SC36, SC47, and SC50) were first observed with wilting symptoms 15 days after transplanting in the Pyeongchang and Hwacheon areas. The cultivars showed disease severity of more than $66.8 \%$ and highly susceptible symptoms such as wilting and heavy root galls. Symptoms of wilting and root galls were observed later in Suwon after the rainy season (Table 2, 3).

The clubroot disease is difficult to control in Chinese cabbage cultivation because the pathogen survives in the soil for a long time as resting spores. For cultural control practices, crop rotation is the most frequently recommended management strategy. Crop rotation is an effective management when combined with other treatments or in fields where Brassica crops have not been grown (Kim et al., 2003; Tremblay et al., 1999). The disease is especially serious in organic Brassica crops (Murakami et al., 2002). The resting spores of $P$. brassicae may remain capable of initiating new infections for seven years or longer in the absence of host plants, as well as a motile zoospore that can swim in wet soils. More than $97 \%$ of total populations of clubroot pathogens are distributed within the $5 \mathrm{~cm}$ depth of top soil (Kim et al., 2000).

Among the 50 cultivars of Chinese cabbage tested in this study, only nine cultivars showed low disease severity $(0-20.0 \%)$ of clubroot 49 days after transplanting in the three open fields. Seven cultivars, SC05, SC06, $\mathrm{SC} 07$, SC09, SC11, SC17, and SC36, showed the moderate resistance scored as disease severity of less than $20.0 \%$ and delayed wilting symptoms and rare root galls. Only, two cultivars, Chuwol (CB22) and Gohyangssam (CB23) showed high resistance to clubroot disease until the harvest season in all of the three fields. These results indicate that two commercial cultivars may be useful candidate's cultivars for organic Chinese 
Table 2. Clubroot disease severity of 50 commercialized Chinese cabbage cultivars in 2011

\begin{tabular}{|c|c|c|c|c|c|c|c|}
\hline \multirow{2}{*}{ Cultivars } & \multicolumn{3}{|c|}{ Severity of clubroot disease $(\%)^{\mathrm{a}}$} & \multirow{2}{*}{ Cultivars } & \multicolumn{3}{|c|}{ Severity of clubroot disease (\%) } \\
\hline & Hwacheon & Suwon & Pyeongchang & & Hwacheon & Suwon & Pyeongchang \\
\hline $\mathrm{SC} 01$ & 20 & 20 & 40 & SC26 & 100 & 66.7 & 100 \\
\hline $\mathrm{SC} 02$ & 13.3 & 0 & 26.7 & $\mathrm{SC} 27$ & 0 & 40 & 20 \\
\hline $\mathrm{SC} 03$ & 13.3 & 13.3 & 40 & $\mathrm{SC} 28$ & 13.3 & 0 & 26.7 \\
\hline $\mathrm{SC} 04$ & 20 & 0 & 20 & $\mathrm{SC} 29$ & 100 & 66.7 & 100 \\
\hline $\mathrm{SC} 05$ & 20 & 20 & 13.3 & SC30 & 100 & 66.7 & 100 \\
\hline SC06 & 20 & 13.3 & 20 & SC31 & 100 & 26.7 & 80 \\
\hline $\mathrm{SC} 07$ & 13.3 & 13.3 & 20 & SC32 & 53.3 & 13.3 & 66.7 \\
\hline SC08 & 100 & 46.7 & 53.3 & SC33 & 53.3 & 13.3 & 66.7 \\
\hline SC09 & 6.7 & 13.3 & 20 & SC34 & 100 & 26.7 & 100 \\
\hline $\mathrm{SC} 10$ & 33.3 & 33.3 & 66.7 & SC35 & 80 & 66.7 & 20 \\
\hline SC11 & 13.3 & 6.7 & 20 & SC36 & 6.7 & 6.7 & 20 \\
\hline $\mathrm{SC} 12$ & 53.3 & 33.3 & 80 & SC37 & 13.3 & 0 & 33.3 \\
\hline $\mathrm{SC} 13$ & 66.7 & 40 & 80 & SC38 & 66.7 & 40 & 100 \\
\hline $\mathrm{SC} 14$ & 13.3 & 26.7 & 40 & SC39 & 6.7 & 20 & 33.3 \\
\hline SC15 & 33.3 & 6.7 & 66.7 & SC40 & 26.7 & 33.3 & 80 \\
\hline SC16 & 33.3 & 6.7 & 80 & SC41 & 26.7 & 53.3 & 93.3 \\
\hline $\mathrm{SC} 17$ & 6.7 & 13.3 & 20 & $\mathrm{SC} 42$ & 66.7 & 53.3 & 100 \\
\hline SC18 & 33.3 & 20 & 100 & $\mathrm{SC} 43$ & 66.7 & 20 & 100 \\
\hline SC19 & 46.7 & 13.3 & 100 & SC44 & 33.3 & 20 & 40 \\
\hline SC20 & 33.3 & 33.3 & 20 & $\mathrm{SC} 45$ & 33.3 & 46.7 & 53.3 \\
\hline SC21 & 40 & 20 & 26.7 & SC46 & 80 & 53.3 & 86.7 \\
\hline $\mathrm{SC} 22$ & 0 & 0 & 0 & $\mathrm{SC} 47$ & 100 & 46.7 & 80 \\
\hline $\mathrm{SC} 23$ & 0 & 0 & 0 & SC48 & 66.7 & 46.7 & 66.7 \\
\hline $\mathrm{SC} 24$ & 60 & 13.3 & 100 & SC49 & 66.7 & 46.7 & 66.7 \\
\hline $\mathrm{SC} 25$ & 26.7 & 0 & 80 & SC50 & 100 & 66.7 & 100 \\
\hline
\end{tabular}

${ }^{\mathrm{a}}$ The disease severity of clubroot symptoms was rated by assigning symptoms based on visual inspection, as well as by measurements of healthy and diseased plants. The data was mean of 15 plants per cultivar.

Table 3. Grade of 50 commercialized Chinese cabbage cultivars based on the disease severity of clubroot in 2011

\begin{tabular}{|c|c|c|c|}
\hline \multirow{2}{*}{$\begin{array}{l}\text { Clubroot resistance } \\
\text { (Disease severity) }\end{array}$} & \multicolumn{3}{|c|}{ Chinese cabbage cultivars } \\
\hline & Hwacheon & Suwon & Pyeongchang \\
\hline $\begin{array}{l}\text { Highly susceptible } \\
\qquad(>=66.8 \%)\end{array}$ & $\begin{array}{l}\text { SC08, SC26, SC29, SC30, SC31, } \\
\text { SC34, SC35, SC46, SC47, SC50 }\end{array}$ & - & $\begin{array}{l}\text { SC12, SC13, SC16, SC18, SC19, } \\
\text { SC24, SC25, SC26, SC29, SC30, } \\
\text { SC31, SC34, SC38, SC40, SC41, } \\
\text { SC42, SC43, SC46, SC47, SC50 }\end{array}$ \\
\hline $\begin{array}{c}\text { Susceptible } \\
(20.1-66.7 \%)\end{array}$ & $\begin{array}{l}\text { SC10, SC12, SC13, SC15, SC16, } \\
\text { SC18, SC19, SC20, SC21, SC24, } \\
\text { SC25, SC 32, SC33, SC 38, SC40, } \\
\text { SC41, SC42, SC43, SC44, SC45, } \\
\text { SC48, SC49 }\end{array}$ & $\begin{array}{l}\text { SC08, SC10, SC12, SC13, SC14, } \\
\text { SC20, SC26, SC27, SC29, SC30, } \\
\text { SC31, SC34, SC35, SC38, SC40, } \\
\text { SC41, SC42, SC45, SC46, SC47, } \\
\text { SC48, SC49, SC50 }\end{array}$ & $\begin{array}{l}\text { SC01, SC02, SC03, SC08, SC10, } \\
\text { SC14, SC15, SC21, SC28, SC32, } \\
\text { SC33, SC35, SC37, SC39, SC44, } \\
\text { SC45, SC48, SC49 }\end{array}$ \\
\hline $\begin{array}{l}\text { Moderate resistant } \\
\quad(0.1-20.0 \%)\end{array}$ & $\begin{array}{l}\mathrm{SC} 01, \mathrm{SC} 02, \mathrm{SC} 03, \mathrm{SC} 04, \mathrm{SC} 05 \\
\mathrm{SC} 06, \mathrm{SC} 07, \mathrm{SC} 09, \mathrm{SC} 11, \mathrm{SC} 14, \\
\mathrm{SC} 17, \mathrm{SC} 28, \mathrm{SC} 36, \mathrm{SC} 37, \mathrm{SC} 39\end{array}$ & $\begin{array}{l}\text { SC01, SC03, SC05, SC06, SC07, } \\
\text { SC09, SC11, SC15, SC16, SC17, } \\
\text { SC18, SC19, SC21, SC24, SC32, } \\
\text { SC33, SC36, SC39, SC43, SC44 }\end{array}$ & $\begin{array}{l}\mathrm{SC} 04, \mathrm{SC} 05, \mathrm{SC} 06, \mathrm{SC} 07, \mathrm{SC} 09 \text {, } \\
\text { SC11, SC17, SC20, SC27, SC25, } \\
\text { SC36 }\end{array}$ \\
\hline $\begin{array}{l}\text { Resistant } \\
\quad(0 \%)\end{array}$ & $\mathrm{SC} 22, \mathrm{SC} 23, \mathrm{SC} 27$ & $\begin{array}{l}\mathrm{SC} 02, \mathrm{SC} 04, \mathrm{SC} 22, \mathrm{SC} 23, \mathrm{SC} 25, \\
\mathrm{SC} 28, \mathrm{SC} 37\end{array}$ & $\mathrm{SC} 22, \mathrm{SC} 23$ \\
\hline
\end{tabular}


cabbage cultivation and will be further tested in vivo (Table 2, 3).

The pathogenic diversity of clubroot disease is one of the best challenges to breed resistant Chinese cabbage varieties. As an example, if resistant Chinese cabbage varieties are grown continuously in the same field, they are likely to change into susceptible progenies (Cho et al., 2002). Also, the level of disease resistance observed depends not only on the combination of host and pathogen genotype but on environmental factors such as soil $\mathrm{pH}$ and moisture content and population density of the $P$. brassicae (Davies and Jones, 2002; Hamilton and Crête, 1978; Kim et al., 1999, 2000). In our results, we were able to select two commercial cultivars, 'Chuwol' and 'Gohyangssam', with a high level of resistance to $P$. brassicae. They scored $0 \%$ clubroot disease incidence, and showed no sign or symptoms of the disease in 49 days after transplanting in three open field. Yoon et al. (2010) reported that, among 53 Chinese cabbage cultivars and lines, several Chinese cabbage cultivars, including 'Gohyangssam', were found resistant to clubroot disease 60 days after transplanting. Also, Jo et al. (2010) reported that 25 CR Chinese cabbage cultivars, including 'Chuwol', were highly resistant to clubroot disease in 35 days after inoculation using soil-drenching method. CR resistant varieties of Chinese cabbage differently showed the resistant level, susceptible, moderate resistant, and resistant depending on the cultivated area and season (Kim et al., 2003).

We confirmed Chuwol and Gohyangssam as clubroot resistant cultivars in this study. Both cultivars are mediumsize Chinese cabbage and have yellow inner leaves. While more genetic and epidemiological studies will still be conducted, we recommend these two selected resistant cultivars as candidates for organic Chinese cabbage cultivation.

\section{Acknowledgment}

This research was supported by a grant program (PJ907121032012) funded by the Rural Development Administration (RDA), Republic of Korea in 2012.

\section{References}

Cho, K. S., Han, Y. H., Lee, J. T., Hur. E. J., Yang, T. J. and Woo, J. G. 2002. Pathogenic differentiation of Plasmodiophora brassicae and selection of Chinese cabbage cultivars resistant to clubroot disease in highland. Korean J. Breed. Sci. 34: 168173.

Davies, G. and Jones, C. 2002. The effect of organic amendments on clubroot (Plasmodiophora brassicae). In: Proceedings of the UK Organic Research 2002 Conference. Organic Centre Wales, Institute of Rural Studies, University of Wales Aberystwyth. pp. 223-224. (http://orgprints.org/8406).

Dixon, G. R. 2009. The occurrence and economic impact of Plasmodiophora brassicae and clubroot disease. J. Plant Growth Regul. 28: 194-202.

Donald, E. C., Porter, L. J., Fraggian, R. and Lancaster, R. A. 2006. An integrated approach to the control of clubroot in vegetable brassica crops. Acta Hort. (ISHS) 706: 283-300.

Hamilton, H. A. and Crête, R. 1978. Influence of soil moisture, soil $\mathrm{pH}$, and liming sources on the incidence of clubroot, the germination and growth of cabbage produced in mineral and organic soils under controlled conditions. Can. J. Plant Sci. 58: 45-53.

Jo, S. J., Jang, K. S., Choi, Y. H., Kim, J. C. and Choi, G. J. 2010. Convenient screening method of Chinese cabbage for resistance to Plasmodiophora brassicae using soil-drenching inoculation. Res. Plant Dis. 16: 279-284. (In Korean)

Kim, C. H., Cho, W. D. and Kim, H. M. 1999. Survey of field conditions of clubroot disease incidence of Chinese cabbage in major production areas and ecology of root gall development. Plant Dis. Agric. 5: 77-83.

Kim, C. H., Cho, W. D. and Kim, H. M. 2000. Some environmental factors affecting germination and survival of resting spores of Plasmodiophora brassicae. Korean J. Pestic. Sci. 4: 66-71.

Kim, C. H., Cho, W. D. and Lee, S. B. 2003. Review of researches on clubroot disease of Chinese cabbage in Korea and future tasks for its management. Res. Plant Dis. 9: 57-63. (In Korean)

Kim, D. W. and Oh, J. H. 1997. Incidence, pathogenicity of clubroot fungus (Plasmodiophora brassicae) and varietal resistance in Chinese cabbage. Korean J. Plant Pathol. 13: 95-99.

Murakami, H., Tsushima, S., Kuroyanagi, Y. and Shishido, Y. 2002. Reduction of resting spore density of Plasmodiophora brassicae and clubroot disease severity by liming. Soil Sci. Plant Nutr. 48: 685-691.

Pia, Z. Y., Deng, Y. Q., Choi, S. R., Park, Y. J. and Lim, Y. P. 2004. SCAR and CAPS mapping of $\mathrm{CRb}$, a gene conferring resistance to Plasmodiophora brassicae in Chinese cabbage (Brassica rapa ssp. perkinensis). Theor. Appl. Genet. 108: 1458-1465.

Tremblay, N., Bêlec, C., Lawrence, H. and Carisse, O. 1999. Clubroot of crucifers-control strategies. Agriculture and AgriFood Canada. Saint-Jean-Sur-Richelieu, Quebec, Canada. 3 pp.

Voorrips, R. E. 1995. Plasmodiophora brassicae: aspects of pathogenesis and resistance in Brassica oleracea. Euphytica 83: 139-146.

Yeoung, Y. R., Kim, J. H., Kim, B. S., Jeon, J. Y. and Yoon, C. S. 2003. Effects of beneficial antagonists (Bacillus sp., Pseudomonas sp., and Trichoderma sp.) on control of clubroot 
of Chinese cabbage. Korean J. Hort. Sci. Technol. 21: 194198.

Yoon, C. S., Jung, E. K., Lee, S. J., Zhang, Y., Lee, J. E. and Kim, B. S. 2010. Screening of resistant Chinese cabbage cultivars against clubroot (Plasmodiophora brassicae) for cultivation in
Highland. Res. Plant Dis. 16: 59-65. (In Korean) Yoshikawa, H. 1981. Breeding for clubroot resistance in Chinese cabbage. In: Chinese cabbage, ed. by N. S. Taleker and T. D. Griggs, pp. 405-413. AVRDC, Tainan. 